\title{
Characteristics of fads2 gene expression and putative promoter in European sea bass (Dicentrarchus labrax): Comparison with salmonid species and analysis of CpG methylation
}

Florian Geay ${ }^{\mathrm{a}}$, José Zambonino-Infante ${ }^{\mathrm{a}}$, Richard Reinhardt ${ }^{\mathrm{b}}$, Heiner Kuhl ${ }^{\mathrm{b}}$, Ester Santigosa ${ }^{\mathrm{a}}$, Chantal Cahu $^{\mathrm{a}}$, David Mazurais ${ }^{\mathrm{a},{ }^{*}}$

\author{
a Ifremer, UMR 1067, Departement Physiologie Fonctionnelle des Organismes Marins, Technopôle \\ Brest-Iroise, BP 70, 29280 Plouzané, France \\ ${ }^{\mathrm{b}}$ Max Planck Inst Mol Genet, D-14195 Berlin, Germany
}

\author{
*: Corresponding author: D. Mazurais, Tel. : +332 9822 44 87; Fax: +33 2982243 66, \\ email address: David.Mazurais@ifremer.fr
}

\begin{abstract}
:
Marine fish species exhibit low capacity to biosynthesise highly unsaturated fatty acid (HUFA) in comparison to strict freshwater and anadromous species. It is admitted that the Delta(6) desaturase (FADS2) is a key enzyme in the HUFA biosynthetic pathway. We investigated by quantitative PCR the relative amounts of FADS2 mRNA in European sea bass (Dicentrarchus labrax) in comparison with a salmonid species, the rainbow trout (Oncorhynchus mykiss L.). The analysis of the expression data was performed regarding the difference of the characteristics of a critical fragment of the fads2 gene promoter between sea bass and Atlantic salmon. The lower level of fads 2 gene expression observed in sea bass suggested that fads2 gene putative promoter, which exhibited an E-box like Sterol Regulatory Element (SRE) site but lacked a Sp1 site, is less active in this marine species. The cytosine methylation of CpG sites in the putative promoter region including E-box like SRE and NF-Y binding sites of sea bass fads2 gene was also investigated following a nutritional conditioning of larvae. However, no significant difference of CpG methylation could be found for any of the 28 CpGs analysed between larvae fed diet with high or low HUFA contents. In conclusion, the present data revealed lower constitutive expression of the fads2 gene possibly related to different characteristics of gene promoter in sea bass in comparison with salmonid species, and indicated that long-term conditioning of fads 2 gene expression did not influence the methylation of the gene promoter at potential SRE binding site.
\end{abstract}

\section{Highlights}

E. sea bass and salmonid fads2 gene promoters exhibit different characteristics. Constitutive fads2 expression is lower in E. sea bass compared to Rainbow trout. Nutritional conditioning do not influence the methylation of SRE binding site.

Keywords: FADS2; Sea bass; Gene expression; Promoter; Methylation 


\section{Introduction}

It is well documented that strict marine fish species exhibit lower HUFA biosynthesis capacities than anadromous species such as salmonids (Leaver et al., 2008). This characteristic is highlighted in experiments investigating the impact of dietary fish oil substitution by vegetable oil on the flesh fatty acid contents and on some physiological parameters in different fish species (Menoyo et al., 2005; Montero et al., 2010; Montero et al., 2005; Peng et al., 2008). Marine fish are unable to convert PUFA into HUFA at a physiologically significant rate due to apparent deficiencies in one or more steps in the biosynthetic pathway (Ghioni et al., 1999; Tocher and Ghioni, 1999). The low level of HUFA biosynthesis from vegetable precursors in marine fish species including Atlantic cod (Gadus morhua L.) and European sea bass (Dicentrarchus labrax L.) could be explained by a deficiency in FADS2 activity (Geay et al., 2010; Tocher et al., 2006). Since fads2 gene has been cloned from several marine fish species (Zheng et al., 2004), the regulation of its expression has been examined during the last decade.

Globally in eukaryotes, the regulation of gene expression can occur at different steps ranging from DNA-RNA transcription to post-translational modification of protein (O'Malley et al., 1977). Transcription is promoted by a DNA sequence, called promoter, typically located upstream from the start site of transcription. The level of gene transcription is greatly dependant on the binding of RNA polymerase and transcription machinery on specific sequences of the promoter. The regulation of gene transcription can thus involve the interaction of transcription factors with the transcription machinery as well as changes in DNA structure (epigenetic process including CpG dinucleotide methylation) which influence accessibility of promoter sequences. It is now well admitted that some transcription factors such as Sterol Regulatory Element Binding Proteins (SREBPs) can act as nutrient sensor to stimulate the basal fads2 gene transcription in vertebrates (Nakamura and Nara, 2002). It has also been shown in mammals that a regulation of the methylation in a CpG rich region of the fads2 gene promoter can modulate its expression contributing to the pathology of hyperhomocysteinemia (Devlin et al., 2007).

In the cod, the deficiency in FADS2 activity can be explained by both a decrease of the level of basal expression and nutritional regulation of fads2 gene compared to Atlantic salmon (Tocher et al. 2006). The comparative analysis of fads2 gene promoters of salmon and cod performed by Zheng et al. (2009) indicated that this deficiency could be related to a less active promoter in cod. In this regard, the same authors identified a potential Sp1 transcription factor binding site required for basal fads2 gene expression of the salmon which was absent in cod promoter. Sp1 has been shown in mammals to cooperate extensively with NF-Y and SREBP1 in order to coordinate the expression of thousands genes involved in several metabolic pathways in liver (Reed et al. 2008). Contrary to cod, sea bass exhibits higher FADS2 and SREBP1 messenger amounts when fed vegetable oil (Geay et al., 2010; Gonzáles-Rovira et al., 2009). However, despite this stimulation of fads2 gene transcription, the activity of the corresponding enzyme in sea bass liver is not enhanced (Mourente and Dick, 2002; Mourente et al., 2005) and is lower than the activities measured in salmonids (Zheng et al., 2005). A post transcriptional regulation of fads2 gene expression in sea bass has been recently suggested to explain this discrepancy (Geay et al., 2010), but until now, little is known about the relative basal amounts of FADS2 transcripts in sea bass compared to salmonids.

It has been suggested that lower HUFA biosynthesis capacities could be explained in marine fish species by the availability of preys enriched in HUFA in their natural environment resulting in the absence of pressure and in dysfunction of the HUFA synthesis pathway throughout evolution (Tocher, 2003). Interestingly, Vagner and coll. indicated that the fads2 gene transcription could be positively and durably regulated by a nutritional conditioning during the larval stage in sea bass (Vagner et al., 2007). The molecular mechanism involved in this induction is not known but could possibly involve gene imprinting through epigenetic regulation such as methylation of CpG dinucleotides. 
In the present study, we have analysed by quantitative PCR the relative quantities of FADS2 messengers in the liver and intestine of sea bass compared with a salmonid species, the rainbow trout. In parallel, we have investigated the characteristics of a putative FADS2 promoter, the potential transcription factors sites and CPG rich islands from sequence recently obtained by Santigosa et al. (2010). Moreover, we hypothesized that cytosine methylation at CpG sites in the promoter region of fads2 gene could be responsible for the nutritional conditioning of HUFA biosynthesis pathway during sea bass larval development. To test this hypothesis, we have analysed the methylation of CpG rich regions, including NF$Y$ and E-box like SRE sites from individual genomic DNA of fish larvae fed fish oil or vegetable oil based diets.

\section{Materials and methods}

\subsection{Sea bass and rainbow trout juveniles breeding}

Sea bass and rainbow trout were fed with two commercial diet in order to cover their respective nutritional requirements such as HUFA [For sea bass: crude protein: $43 \%$ dry matter (DM), crude fat: 20\% DM, EPA + DHA 7.5\% lipid. For rainbow trout: crude protein: 40\% DM, crude fat: $23 \%$ DM, EPA + DHA 11.5\% lipid]. Rainbow trout $(473 \mathrm{~g} \pm 45 \mathrm{~g})$ were obtained from the experimental station of Sizun (INRA institute, France) while sea bass $(565 \mathrm{~g} \pm 62 \mathrm{~g})$ were bred in the Ifremer institute (Brest, France). Sampling were performed in winter after 10-12 hours fasting for both species. The relative quantity of FADS2 messengers were individually measured in the liver and intestine of five fishes (males and females) from each species.

\subsection{Larvae conditioning}

Two iso-lipid and iso-protein diets were formulated for the nutritional conditioning experiment (Table 1). Lipids in the control diet (diet $\mathrm{H}$ ) were brought by fish origin ingredients completed by a blend of lecithin (soybean and rapeseed). In the experimental diet (diet $L$ ), most of fish meal was replaced by defatted fish meal while fish oil was substituted by soybean oil. Both diets provided similar balance of saturates, monoenes and PUFA but different HUFA contents. The fatty acid composition of the two diets is given in Table 1. Sea bass larvae obtained from the Station of Palavas-les-Flots (Ifremer institute, France) were distributed randomly into five $35 \mathrm{~L}$ cylindrical tanks at 2800 fishes per tank. The tanks were supplied with non-recirculated seawater at a constant temperature of $20^{\circ} \mathrm{C}$ and were subjected to a photoperiod of $12 \mathrm{~h}$ light: $12 \mathrm{~h}$ dark. Both diets were distributed ad libitum automatically $12 \mathrm{~h} /$ day during all the larvae stage. After the metamorphose (around 45 days post-hatching), all fish nourished with the same diet were pooled in a $1000 \mathrm{~L}$ tank and after a acclimatation period of two days, 20 fishes per condition were sampled for liver analysis. Real time PCR investigation of FADS2 and 18S in liver were performed from 20 samples per group while methylation analysis of the FADS2 promoter were investigated with 10 samples per group. These experiments have been carried out in accordance with The Code of Ethics of the World Medical Association (Declaration of Helsinki).

\subsection{RNA extraction and real-time quantitative-PCR analysis}

Total RNA originated from either larval (liver) and adult (liver and intestine) tissues were extracted using Trizol reagent (Invitrogen, USA), and quantified by measuring absorbance at 
$260 \mathrm{~nm}$ in a spectrophotometer (Nanodrop Labtech, France). The reverse transcription was performed using the kit QuantiTect ${ }^{\circledR}$ Reverse Transcription (QIAGEN) including a genomic DNA elimination reaction. Reactions were carried out in $20 \mu \mathrm{l}$ of volume containing $1 \mu \mathrm{g}$ of total RNA, $1 \mu \mathrm{l}$ Quantiscript Reverse Transcriptase, $4 \mu \mathrm{l}$ Quantiscript RT buffer (5X) and $1 \mu \mathrm{l}$ Primer Mix and sterile MilliQ water. Fads2 gene as well as the housekeeping Elongation Factor 1 alpha $(E F 1 \alpha)$ and $18 S$ genes relative expressions were determined by using real time PCR. Primers (listed in table 2) used for real time PCR were designed using primer 3 software v. 0.4 .0 (http://frodo.wi.mit.edu/primer3/). The amplicon sizes ranged from 75 to 200 nucleotides. For the comparison of fads2 gene expression between sea bass and rainbow trout, FADS2 (sea bass: GenBank ID: EU439924; rainbow trout: AF301910.1) and EF1 $\alpha$ (seabass: GenBank ID: AJ866727; rainbow trout: AF498320.1) primers were designed in order to cross-hybridize with sequences in both species. For the larvae conditioning study, specific primers were designed for sea bass FADS2 (GenBank ID: EU439924) and 18S (GenBank ID: AY831388.1) sequences.

Real-time PCR efficiencies $(E)$ were automatically determined for each primer pair by the Bio-Rad IQ5 software using standard curves obtained from serial dilution of a pool of the different cDNA samples. $E$ was calculated according to the equation: $E=10 e[-1 /$ slope]. This analysis ensures that $E$ ranged from $97 \%$ to $100 \%$ for each primer pair. Primers, PCR efficiencies and sequences are listed in table 2.

18S RNA was chosen to provide an internal control for investigation of fads2 gene expression at 45 days post hatching in sea bass. Indeed, contrary to EF1 we did not observe any significant difference between $\mathrm{Ct}$ values for $18 \mathrm{~S}$ between the $\mathrm{H}$ and $\mathrm{L}$ dietary groups ( $\mathrm{t}-$ student test, $p>0$. 1). Its stability was also assessed by a low coefficient of variation over all the samples (CV < 5\%). EF1 $\alpha$ RNA was chosen as an internal control to compare fads2 gene expression between rainbow trout and sea bass samples since its relative quantity did not exhibit significant difference between samples (CV <5\%).

Real-time PCR amplifications were carried out in triplicate in an I-cycler with an optical module (Bio-Rad, Hercules, CA, USA) in a final volume of $15 \mu$ l containing $7.5 \mu \mathrm{l}$ of SYBR Green Supermix 2X (Biorad, Hercules, CA, USA), $0.5 \mu$ of each primer $(10 \mathrm{mM})$ and $5 \mu \mathrm{l}$ of CDNA (1/50 dilution). The PCR program consisted of an initial DNA denaturation of $94^{\circ} \mathrm{C}$ for $90 \mathrm{~s}$, followed by 45 cycles at $95^{\circ} \mathrm{C}$ for $30 \mathrm{~s}, 60^{\circ} \mathrm{C}$ for $60 \mathrm{~s}$ and 80 cycles at $95^{\circ} \mathrm{C}$ for $10 \mathrm{~s}$. A triplicate of the amplification reaction was performed for each sample. Relative quantity of messenger is automatically normalized and measured by Bio-Rad IQ5 software using $\Delta \Delta \mathrm{Ct}$ method (Ct for Cycle threshold):

FADS2 Normalized Expression in sample $1=($ FADS2 Relative Quantity in sample 1$) /($ EF1 or 18S Relative Quantity in sample 1)

with Relative Quantity in sample 1 for a gene $i=\mathrm{E}_{(\text {gene i) }} \mathrm{Ct}$ (sample 2) - Ct (sample 1)

Each run included negative controls (total RNA sample) to ensure that PCR product did not result from genomic DNA contamination and blank controls (water).

Melting curve analysis was systematically performed for all genes in order to verify the specificity of the PCR product. Furthermore, after amplification, the PCR products were checked by agarose gel electrophoresis and sequenced (Millegen, France).

\subsection{DNA extraction and bisulfite treatment}

DNA extraction from liver was performed using the "Nucleospin ${ }^{\circledR}$ Tissue" kit and quantified by measuring the absorbance at $260 \mathrm{~nm}$ with a spectrophotometer (Nanodrop Labtech, France).

The bisulfite treatment was realised from $500 \mathrm{pg}$ of DNA per sample using the EZ DNA methylation-GoldTM kit (Zymo Research) and stored at $-20^{\circ} \mathrm{C}$ until analysis. 


\subsection{Promotor methylation}

Primer sequences for fads2 gene promoter were designed with MethPrimers Software (http://www.urogene.org/methprimer) generating a 588-bp targeted PCR product but modified to introduce GS-FLX bead adaptor and specific identity tag (Multiplex Identifiers, MID) for each sample. Specific primers were the following: 5'TTAAGTTTATATAAGATTTTGAATGTAGGG-3' (Forward) and 5'AAACATATCAAACCACAAAAAATCTA-3' (Reverse); GsFLX adaptors were added on the 5'end of the specific primers: 5'-CGTATCGCCTCCCTCGCGCCATCAG-3' (Adaptor A) and 5'CTATGCGCCTTGCCAGCCCGCTCAG-3' (Adaptor B). MIDs were added between specific primers and GsFLX-adaptors on each side of the PCR product in order to perform a bidirectionnal sequencing. In this study, the combination of 20 different MID and 1/8 of a GsFLX Titanium PicoTiterPlate (454 Life Sciences, Roche Diagnostics) was used to differentiate and identify all samples.

PCR was carried out in a total volume of $50 \mu \mathrm{l}$. The PCR mixture contained $0.4 \mathrm{pmol}$ of each primer, 12 pmol deoxynucleoside triphosphate, $1 \times$ PCR buffer, one unit of Taq Qiagen (Qiagen), and $40 \mathrm{ng}$ bisulfated DNA. PCR conditions were $94^{\circ} \mathrm{C}$ for $30 \mathrm{~s}, 50^{\circ} \mathrm{C}$ for $30 \mathrm{~s}$ and $72^{\circ} \mathrm{C}$ for $1 \mathrm{~min}, 50$ cycles.

The amplified PCR products were then identified on $2 \%$ agarose gels. Images of ethidium bromide-stained agarose gels were acquired with a CCD camera (Bio-Rad, USA). Amplicons containing bead adaptor and MID were purified on Nucleofast 96 PCR Plates (MachereyNagel) according to manufacturer instructions. Next, amplicons were quantified by QuantiT ${ }^{\mathrm{TM}}$ PicoGreen (Invitrogen), fixed on beads and amplified in microemulsion by GS FLX Titanium emPCR Kit (454 Life Sciences, Roche Diagnostics). Amplified beads were then purified and enriched according to manufacturer's instructions, counted with the Beckman Coulter Z1 Particle Counter and deposited on the GS FLX Titanium PicoTiterPlate. Finally, Pyrosequencing reaction was performed with the GS FLX Titanium Sequencing Kit (454 Life Sciences, Roche Diagnostics) on Genome Sequencer FLX Instrument (454 Life Sciences, Roche Diagnostics).

\subsection{Statistical analysis}

All the results are presented as mean values and standard deviations (SD). Gene expression $(q P C R)$ and DNA methylation were tested by student t-test $(p<0.05)$ using the Statistica biosoft 8.0. 


\section{Results}

\subsection{Organisation of sea bass fads2 gene}

We have previously reported a sequence of $11,153 \mathrm{bp}$ corresponding to sea bass fads2 gene (FP671139). The alignment of sea bass FADS2 cDNA sequences listed in databases (AM746703.1, AM746707.1, AM746706.1, AM746705.1, AM746704.1, EU647692.1) with the complete gene indicated that the gene consists of 13 exons with a translation start site (ATG) located in exon 2 and the stop codon in exon 13 (Figure 1). A potential transcription start site (TSS1) assumed to be the first base of the 5'non-coding exon has been determined based on the information originated from AM746703.1, AM746707.1, AM746706.1, AM746705.1 and AM746704.1 sequences. A second possible transcription start site (TSS2) can also be assumed based on the first base of the 5'non-coding exon of sequence EU647692.1 which can correspond to a splicing variant of FADS2.

Alignments of part of the salmon, cod and sea bass FADS2 promoter regions including potential transcription factor elements (Sp1, NF-Y, E-box like SRE) were performed using clustalW (Figure 2). Candidate transcriptional regulatory sequences were selected based on previous work performed by Zheng et al. (2009) who investigated the major sites for promoter activity in cod and salmon. Present alignment showed that areas corresponding to possible E-box like SRE and to a lower degree NF-Y were well conserved across the three species. In contrary, the Sp1 binding site essential for the activity of salmon FADS2 promoter is not found in the sea bass sequence nor in that of cod.

In silico analysis of sea bass FADS2 promoter and 5' end non coding region sequences reveal a relative high $\mathrm{CpG}$ content in the area including the different potential transcription factor element (Figure3). Especially, three CpG dinucleotides are located in the E-box like SRE.

\subsection{Comparison of relative FADS2 mRNA amounts between sea bass and rainbow trout}

The lack of Sp1 site suggesting a less active promoter in sea bass compared to salmonids prompted us to compare the relative amounts of FADS2 mRNA between sea bass and a salmonid species, the rainbow trout. The relative quantity of FADS2 messengers were measured in the liver and intestine of sea bass and rainbow trout fed commercial fish diet by qPCR using primers designed to cross-hybridize FADS2 CDNA in both species (Figure 4). FADS2 transcripts exhibited significant higher levels in the liver (58x) and intestine (42x) of rainbow trout (t-student test, $\mathrm{p}<0.01$ ).

\subsection{Effect of diet on the CpG methylation and FADS2 mRNA levels in sea bass larvae}

Cytosine methylation of the $28 \mathrm{CpG}$ sites including 3 CpG sites that are part of the putative E-box like SRE in FADS2 promoter was analysed at 45 days post hatching in any of 20 sea bass larvae fed high $(n=10)$ and low $(n=10)$ levels of HUFA. While sequencing was performed on individual DNA containing many genomic DNA copies, between 20 and 2000 sequences were read per fish depending on CpG site in order to detect and quantify partial methylation (expressed in percentage). No significant difference of CpG methylation could be detected for any analysed CpG site between the two dietary groups (Figure 5). Globally the mean proportion of methylated DNA per dietary group did not exceed $3 \%$ for any CpG site. The maximal percentage of methylation (15\%) was detected for CpG\#18 site in one fish fed high level of HUFA (data not shown).

In parallel, the relative levels of FADS2 messengers were investigated by quantitative PCR (Figure 6) from hepatic RNA originated from the same fish at 45 days post hatching. Data obtained indicated significant higher FADS2 mRNA levels in larvae fed low HUFA level 
during development (Diet L). No significant correlation could be observed between mRNA levels and promoter methylation rates (data not shown).

\section{Discussion and conclusions}

The present study investigated fads2 gene expression in sea bass through the comparison of FADS2 mRNA amounts and promoter characteristics with salmonid species. We also analysed the methylation status of the putative sea bass fads2 promoter following an early nutritional conditioning of sea bass. The qPCR analysis showed that the relative quantity of FADS2 mRNA was around 50-fold higher in hepatic and intestinal tissues of rainbow trout compared to sea bass when both species are fed commercial fish diet (Figure 4). We can not rule out the possibility that the primers used for FADS2 cDNA amplification cross-hybridised with FADS1 cDNA, especially in rainbow trout since fads2 and fads1 gene sequences have been shown to exhibit high identity in different salmonid species (Zheng et al., 2005). Nevertheless, it is unlikely that the high difference of relative FADS2 mRNA amounts detected between rainbow trout and sea bass in the present study could be only related to cross-hybridization of primers on the different desaturase subtypes. This data revealing low expression of FADS2 in the liver of sea bass is in agreement with previous data showing a greater amount of FADS2 mRNA in brain than in liver (Gonzáles-Rovira et al., 2009; Santigosa I Culi et al., 2010) in this species while in salmon, FADS2 transcripts amounts were similar in both tissues (Zheng et al., 2005). The difference of constitutive fads2 gene transcription has already been suggested to explain the difference of basal FADS2 activity between salmonids and a marine fish species, the cod (Tocher et al., 2006).

A recent investigation of the salmon promoter revealed that a site potentially recognized by the Sp1 transcription factor was required for the full expression of the salmon fads2 gene (Zheng et al., 2009). The same authors suggested that the lack of a Sp1-like site in the corresponding region of the cod fads 2 gene promoter may be responsible for the difference in the constitutive expression of fads2 gene between the two species. In agreement with this hypothesis we could not find a Sp1 like site in the corresponding region of the sea bass fads2 gene putative promoter (Figure 2). In mammals, Sp1 has been shown to contribute with NF-Y transcription factors to the regulation by SREBP of the expression of several genes involved in cholesterogenic and lipogenic pathways (Amemiya-Kudo et al., 2002; Teran-Garcia et al., 2007). In the present study, a region having a striking analogy to the potential NF-Y sites and SREBP binding sites in salmon and mammals was located in a similar position in the putative promoter of the sea bass fads2 gene. It has been shown in mammals that these sites mediated the negative regulation by HUFA on fads2 gene expression (Nara et al., 2002). The conservation of these sites in sea bass is in agreement with the known down-regulation of fads2 gene expression by HUFA in this specie (Geay et al., 2010; Gonzáles-Rovira et al., 2009). Moreover Geay et al. (2010) suggested that SREBP1 transcription factor could be involved in the molecular mechanisms underpinning the regulation of fads2 gene expression since its expression was also regulated by HUFA. Altogether, the lower constitutive fads 2 gene expression in sea bass compared to salmonids may be explained by the lack of Sp1 sites while the similar level of gene stimulation by HUFA between these both species could be related to the conservation of SREBP and NF-Y sites.

As suggested by Vagner et al. (2007), the fads2 gene expression in juvenile sea bass could be significantly enhanced by a nutritional conditioning with a HUFA-low diet during larval stage. This effect on fads2 gene expression was associated to a better capacity of fish to adapt to a deficient HUFA diet. It is well documented that epigenetic mechanisms altering chromatin conformation and the accessibility of transcription factors can be induced by transient nutritional stimuli occurring at critical ontogenic stages resulting in lasting influences on the expression of various genes (Waterland and Garza, 1999). In mammals, fads2 gene expression in the liver has been shown to be down-regulated by the hypermethylation of CpG sites in the promoter, contributing to the hyperhomocysteinemia desease (Devlin et al., 2007). In the present study, we compared at 45 days post hatching the methylation of 28 
CpG dinucleotides in the putative promoter region of fads2 gene, and more specifically around the SRBEP1 binding site, between larvae fed high and low HUFA level diet (Figure 3). QPCR analysis revealed a stimulation of fads2 gene expression in larvae fed low HUFA diet at 45 days post hatching (Figure 6) and lasting effects during juvenile stage similar to data obtained by Vagner et al. (2007) revealing nutritional conditioning (data not shown). However, no significant difference of CpG methylation could be found for any of the $28 \mathrm{CpGs}$ analysed (Figure 5). Thus, the nutritional conditioning of fads2 gene expression of sea bass during the larval period cannot be associated to a methylation of the $3 \mathrm{CpGs}$ located in the putative SREBP binding site in the putative promoter. It has to be stressed the fact that the present study can not definitively rule out methylation as the responsible mechanism for the stimulation of fads2 gene expression by nutritional conditioning during sea bass larvae development since not every CpG site was examined in the promoter, particularly those

located downstream from the analysed promoter area. If methylation is not responsible for the long term nutritional influence of fads2 gene expression, other epigenetic mechanism such as histone acetylation could be considered.

In conclusion, the present data revealed novel insight concerning characteristics of fads2 gene expression and putative promoter in sea bass. Comparison with salmonids species indicated a lower constitutive expression of the fads2 gene associated with absence of Sp1 site in its promoter. Finally, long-term conditioning of fads2 gene expression during the early nutrition phase was not associated with a methylation of the gene promoter at the SREBP binding site.

\section{Acknowledgements}

This work was partly supported by Marine Genomic Europe (MGE) and by Genomics and "Blue Chemistry" axis of Europole Mer. The authors thank Elisabeth Desbruyeres for her assistance in gene expression analysis. E Santigosa was supported by a post doctoral fellowship from the Fundacion Alfonso Martin Escudero (Spain). 


\section{References}

Amemiya-Kudo, M., Shimano, H., Hasty, A.H., Yahagi, N., Yoshikawa, T., Matsuzaka, T., Okazaki, H., Tamura, Y., lizuka, Y., Ohashi, K., Osuga, J., Harada, K., Gotoda, T., Sato, R., Kimura, S., Ishibashi, S., Yamada, N., 2002. Transcriptional activities of nuclear SREBP-1a,1c, and-2 to different target promoters of lipogenic and cholesterogenic genes. J. Lipid Res., $43,1220-1235$.

Devlin, A.M., Singh, R., Wade, R.E., Innis, S.M., Bottiglieri, T., Lentz, S.R., 2007. Hypermethylation of Fads2 and altered hepatic fatty acid and phospholipid metabolism in mice with hyperhomocysteinemia. J Biol Chem, 282, 37082-37090.

Geay, F., Santigosa I Culi, E., Corporeau, C., Boudry, P., Dreano, Y., Corcos, L., Bodin, N., Vandeputte, M., Zambonino-Infante, J.L., Mazurais, D., Cahu, C.L., 2010. Regulation of FADS2 expression and activity in European sea bass (Dicentrarchus labrax, L.) fed a vegetable diet. Comp Biochem Physiol B, 156, 237-243.

Ghioni, C., Tocher, D.R., Bell, M.V., Dick, J.R., Sargent, J.R., 1999. Low C-18 to C-20 fatty acid elongase activity and limited conversion of stearidonic acid, $18: 4(n-3)$, to eicosapentaenoic acid, $20: 5(n-3)$, in a cell line from the turbot, Scophthalmus maximus. Bba-mol. cell. biol. I., 1437, 170-181.

Gonzáles-Rovira, A., Mourente, G., Zheng, X., Tocher, D.R., Pendón, C., 2009. Molecular and functional characterization and expression analysis of a $\Delta 6$ fatty acyl desaturase cDNA of European sea bass (Dicentrarchus labrax L.). Aquaculture, 298, 90-100.

Leaver, M.J., Bautista, J.M., Bjornsson, B.T., Jonsson, E., Krey, G., Tocher, D.R., Torstensen, B.E., 2008. Towards Fish Lipid Nutrigenomics: Current State and Prospects for Fin-Fish Aquaculture. Reviews in Fisheries Science, 16, 73-94.

Menoyo, D., Lopez-Bote, C.J., Obach, A., Bautista, J.M., 2005. Effect of dietary fish oil substitution with linseed oil on the performance, tissue fatty acid profile, metabolism, and oxidative stability of Atlantic salmon. J Anim Sci, 83, 2853-2862.

Montero, D., Mathlouthi, F., Tort, L., Afonso, J.M., Torrecillas, S., Fernandez-Vaquero, A., Negrin, D., Izquierdo, M.S., 2010. Replacement of dietary fish oil by vegetable oils affects humoral immunity and expression of pro-inflammatory cytokines genes in gilthead sea bream Sparus aurata. Fish Shellfish Imm., 29, 1073-1081.

Montero, D., Robaina, L., Caballero, M.J., Gines, R., Izquierdo, M.S., 2005. Growth, feed utilization and flesh quality of European sea bass (Dicentrarchus labrax) fed diets containing vegetable oils: A time-course study on the effect of are-feeding period with a $100 \%$ fish oil diet. Aquaculture, 248, 121-134.

Mourente, G., Dick, J.R., 2002. Influence of partial substitution of dietary fish oil by vegetable oils on the metabolism of [1-C-14]18:3n-3 in isolated hepatocytes of European sea bass (Dicentrarchus labrax). Fish Physiol Biochem, 26, 297-308.

Mourente, G., Dick, J.R., Bell, J.G., Tocher, D.R., 2005. Effect of partial substitution of dietary fish oil by vegetable oils on desaturation and beta-oxidation of [1-C-14]18:3n-3 (LNA) and [1-C-14]20:5n-3 (EPA) in hepatocytes and enterocytes of European sea bass (Dicentrarchus labrax L.). Aquaculture, 248, 173-186.

Nakamura, M.T., Nara, T.Y., 2002. Gene regulation of mammalian desaturases. Biochem Soc Trans, 30, 1076-1079. 
Nara, T.Y., He, W.S., Tang, C.G., Clarke, S.D., Nakamura, M.T., 2002. The E-box like sterol regulatory element mediates the suppression of human Delta- 6 desaturase gene by highly unsaturated fatty acids. Biochem. Biophys. Res.ommun. 296, 111-117.

O'Malley, B.W., Towle, H.C., Schwartz, R.J., 1977. Regulation of Gene Expression in Eucaryotes“ Annual Review of Genetics, 11, 239-275.

Peng, S.M., Chen, L.Q., Qin, J.G., Hou, J.L., Yu, N., Long, Z.Q., Ye, J.Y., Sun, X.J., 2008. Effects of replacement of dietary fish oil by soybean oil on growth performance and liver biochemical composition in juvenile black seabream, Acanthopagrus schlegeli. Aquaculture, 276, 154-161.

Reed, B.D., Charos, A.E., Szekely, A.M., Weissman, S.M., Snyder, M., 2008. Genome-wide occupancy of SREBP1 and its partners NFY and Sp1 reveals novel functional roles and combinatorial regulation of distinct classes of genes. PLoS Genet, 4, e1000133.

Santigosa I Culi, E., Geay, F., Tonon, T., Le Delliou, H., Kuhl, H., Reinhardt, R., Corcos, L., Cahu, C.L., Zambonino-Infante, J.L., Mazurais, D., 2010. Cloning, Tissue Expression Analysis, and Functional Characterization of Two $\Delta 6$-Desaturase Variants of Sea Bass (Dicentrarchus labrax L.). Mar Biotechnol, DOI 10.1007/s10126-010-9264-4.

Teran-Garcia, M., Adamson, A.W., Yu, G., Rufo, C., Suchankova, G., Dreesen, T.D., Tekle, M., Clarke, S.D., Gettys, T.W., 2007. Polyunsaturated fatty acid suppression of fatty acid synthase (FASN): evidence for dietary modulation of NF-Y binding to the Fasn promoter by SREBP-1c. Biochem J, 402, 591-600.

Tocher, D.R., 2003. Metabolism and Functions of Lipids and Fatty Acids in Teleost Fish. Rev. Fisheries Sci. 11, 107-184.

Tocher, D.R., Ghioni, C., 1999. Fatty acid metabolism in marine fish: Low activity of fatty acyl Delta 5 desaturation in gilthead sea bream (Sparus aurata) cells. Lipids, 34, 433-440.

Tocher, D.R., Zheng, X., Schlechtriem, C., Hastings, N., Dick, J.R., Teale, A.J., 2006. Highly unsaturated fatty acid synthesis in marine fish: cloning, functionnal characterization, and nutrionnal regulation of fatty acyl $\Delta 6$ desaturase of Atlantic cod (Gadus morhua L.). Lipids, 41, 1003-1016.

Vagner, M., Infante, U.Z., Robin, J.H., Person-Le Ruyet, J., 2007. Is it possible to influence European sea bass (Dicentrarchus labrax) juvenile metabolism by a nutritional conditioning during larval stage? Aquaculture, 267, 165-174.

Waterland, R.A., Garza, C., 1999. Potential mechanisms of metabolic imprinting that lead to chronic disease. AM J. Clin. Nutr., 69, 179-197.

Zheng, X., Leaver, M.J. Tocher, D.R., 2009. Long-chain polyunsaturated fatty acid synthesis in fish: Comparative analysis of Atlantic salmon (Salmo salar L.) and Atlantic cod (Gadus morhua L.) [DELTA] 6 fatty acyl desaturase gene promoters. Comp. Biochem. Physiol. B, 154 (3),

255-263.

Zheng, X., Seiliez, I., Hastings, N., Tocher, D.R., Panserat, S., Dickson, C.A., Bergot, P., Teale, A.J., 2004. Characterization and comparison of fatty acyl $\Delta 6$-desaturase cDNAs from freshwater and marine teleost fish species. Comp Biochem Physiol B, 139, 269-279. 
Zheng, X., Tocher, D.R., Dickson, C.A., Bell, J.G., Teale, A.J., 2005. Highly unsaturated fatty acid synthesis in vertebrates: new insights with the cloning and characterization of a $\Delta 6$ desaturase of Atlantic salmon. Lipids, 40, 13-24.

\section{Figures Legends}

Figure 1: Alignment of seabass FADS2 gene with cDNA sequences reported for the same species in public databases using NCBI spidey tools (http://www.ncbi.nlm.nih.gov/IEB/Research/Ostell/Spidey/). Official NCBI references of the FADS2 gene and cDNA sequences (FP671139.1, AM746703.1, AM746707.1, AM746706.1, AM746705.1, AM746704.1) are represented on the left. Seabass gene sequence (FP671139.1) is illustrated using black thick line. Grey boxes on cDNA sequences refer to related exons in the gene sequence while dark lines correspond to introns. Gene sequence is numbered relative to the first base of the transcription start site (TSS1), assumed to be the first base of the 5'non-coding exon based on cDNA and EST sequence information. TSS2 correspond to the first base of the 5'non-coding exon based on the sequence EU647692.1.

Figure 2: Alignment of a part of the salmon, cod and seabass FADS2 promoter regions including potential transcription factor element. The numbers indicate the sequence position relative to possible transcriptional start sites (TSS1 for seabass). SP1 binding site and NF-Y binding sites or E-box like sterol regulatory element (SRE) were indicated based on previous work from Zheng et al. (2009) and Nara et al. (2002) respectively.

Figure 3: Fragment of FADS2 promoter sequenced after bisulfite treatment including aproximately 200 nucleotides upstream and 320 nucleotides downstream from the possible transcriptional start site TSS1. The numbers indicate the sequence position relative to TSS1. The predicted transcriptomic factors elements mentioned by Zheng et al. (2009) are underlined. The CpG dinucleotides analysed for methylation are boxed and numbered in bold.

Figure 4: Comparative analysis of European seabass and rainbow trout FADS2 gene expression in liver and intestine. FADS2 expression data are normalized by EF1a. The expression levels were measured from a pool of 5 fishes fed a commercial fish diet for each species. Bars represent the standard deviation measured from 3 technical replicates. Significant differences between expression levels are indicated by an asterisk (t-student test, $\mathrm{p}<0.01)$. 
Figure 5: Analysis of the FADS2 promoter methylation in sea bass larvae fed high (white) and low (grey) levels of HUFA. The percentage of methylation of the $28 \mathrm{CpGs}$ in the FADS2 promoter was analysed after bisulfite pyrosequencing. Values shown are $+/-S E M, n=10$ for each nutritional condition. No significant difference of percentage methylation could be detected between dietary groups throughout different CpG sites (one way anova, $p<0.05$ ).

Figure 6: Analysis of FADS2 expression in the liver of sea bass larvae fed during 45 days high (Diet $H$ ) and low levels (diet $L$ ) of HUFA. Values shown are +/- SE, $n=20$ for each nutritional condition. Expression data are normalised with ribosomal 18S RNA expression. Significant differences between expression levels are indicated by an asterisk (t-student test, $\mathrm{p}<0.01)$. 
TSS1 TSS2 ATG

STOP

$-1523$

$178 \quad 830$

71537629

9630

Gene FP671139.1

AM746703.1

AM746707.1

AM746706.1

cDNA $\{$ AM746705.1

AM746704.1

EU647692.1

EU439924.1

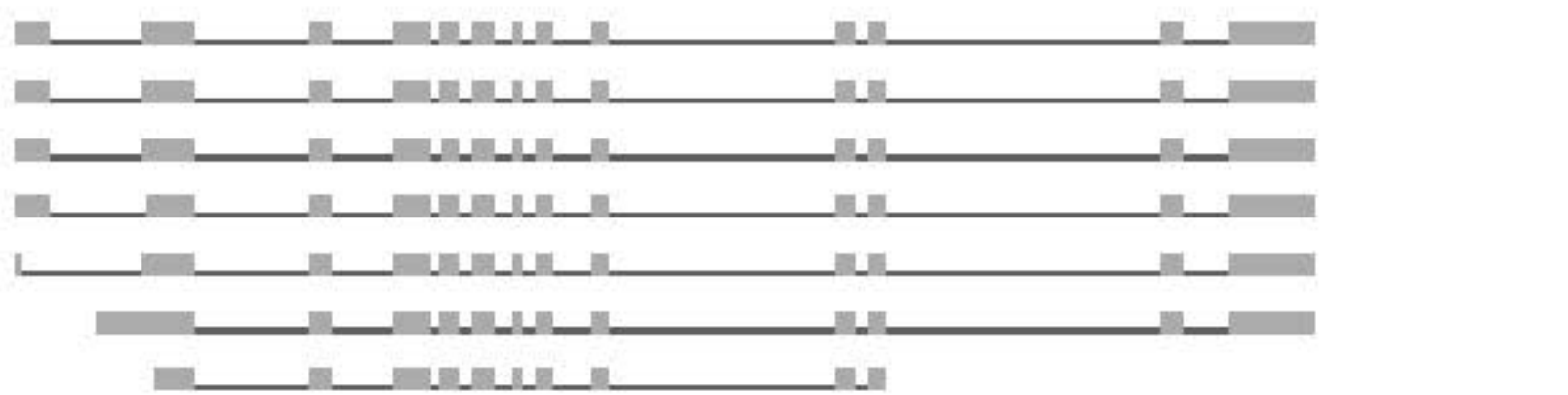




\begin{tabular}{|c|c|c|}
\hline cod & & 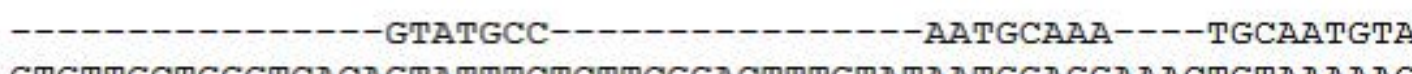 \\
\hline seabass & -194 & GTGTTGCTGGGTCACAGTATTTCTCTTCGGACTTTGTATAATGGAGGAAACTGTAAAAAG \\
\hline non & -342 & 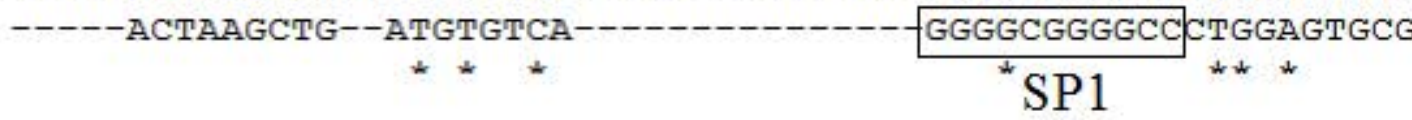 \\
\hline $\begin{array}{l}\text { cod } \\
\text { seabass } \\
\text { salmon }\end{array}$ & & $\begin{array}{l}\text {-CCA-GCATTTCCAGTTCAACTGTA-CTGCTGAAACGCACGCCACACGCACGCCACA-TT } \\
\text {-CGACGCGCTCCCG--CAGACTGTTTCCGTCTGAGCGCAC---AGACG-ACTCTGTAATA } \\
\text { TCCAAGCGTTCT------GATTG----GTTGAAATATGT---GGATGATTGACAGA--- } \\
\star * * * * * \\
* * *\end{array}$ \\
\hline $\begin{array}{l}\text { cod } \\
\text { seabass } \\
\text { salmon }\end{array}$ & & 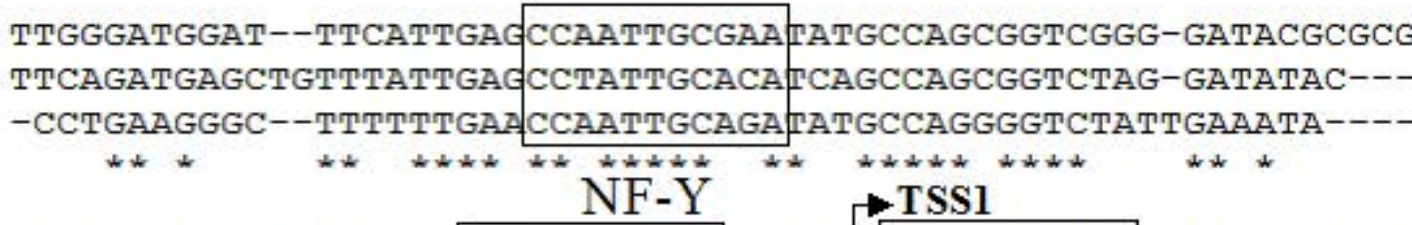 \\
\hline $\begin{array}{l}\text { cod } \\
\text { seabass } \\
\text { salmon }\end{array}$ & & $\begin{array}{c}\text { GATTGGTCCGGGATACGCG } \\
- \text { CGATTGGCCCACCATd }\end{array}$ \\
\hline
\end{tabular}


$-200$ 1

TCACACTGTGGTGTGCTGGGTA

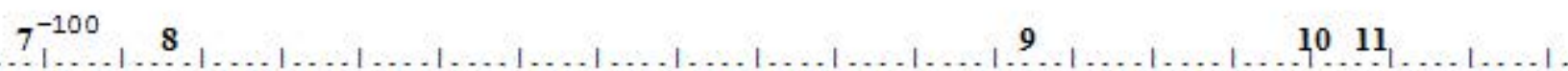

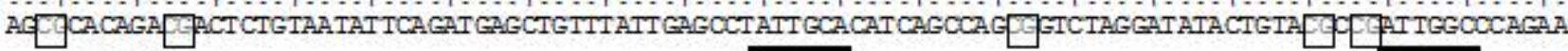

\section{$\rightarrow$ TSS1}

$12 \quad 13 \quad 14$ $\mathrm{NF}-\mathrm{Y}$

NF-Y

$|\ldots| \ldots|\ldots| \ldots|\ldots| \ldots|\ldots| \ldots|\ldots| \ldots|\ldots| \ldots|\ldots| \ldots|\ldots| \ldots|\ldots| \ldots 1 \ldots 1 \ldots$

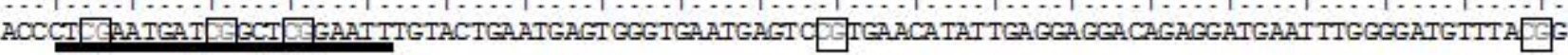
E-box like SRE

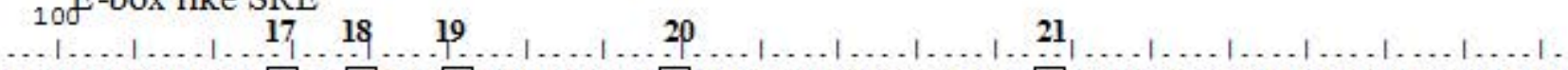

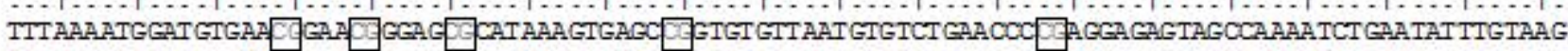

200

22

23

24

25

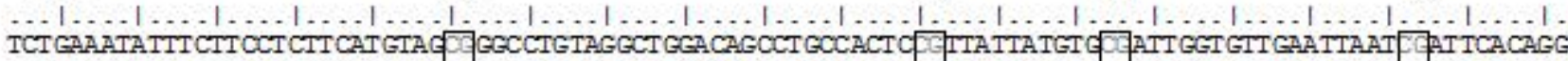

$26^{300} \quad 27$

28

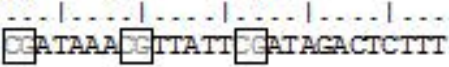



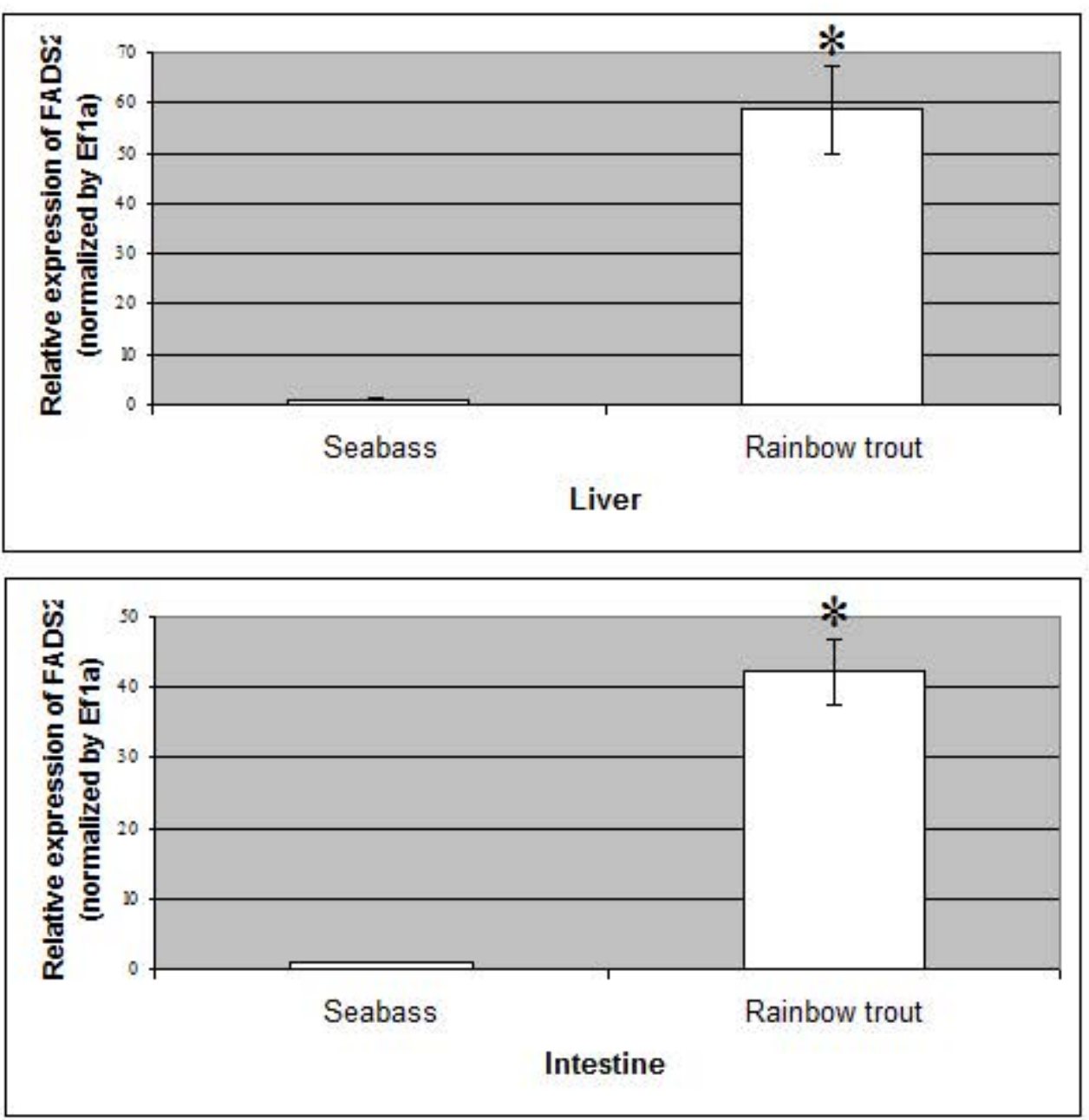


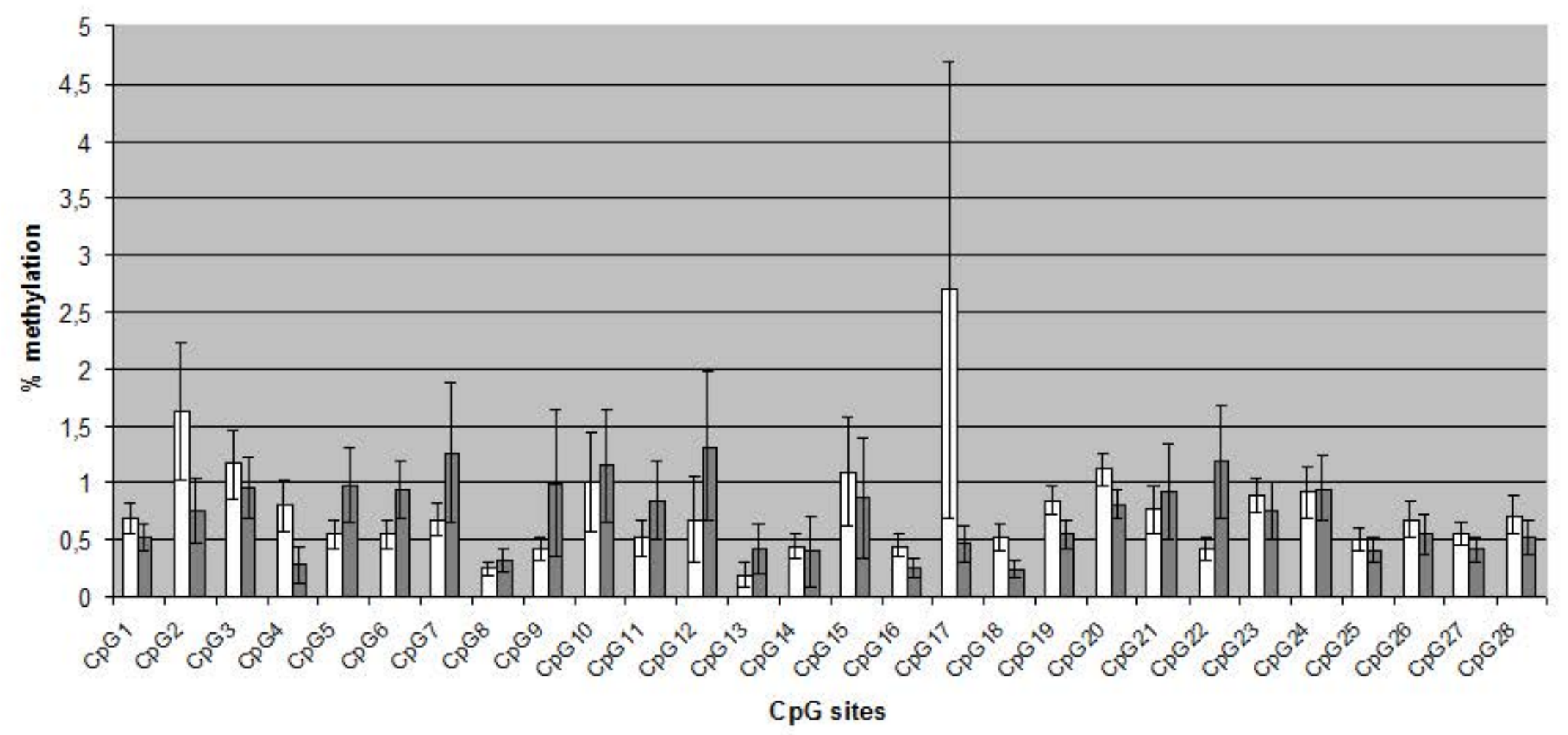




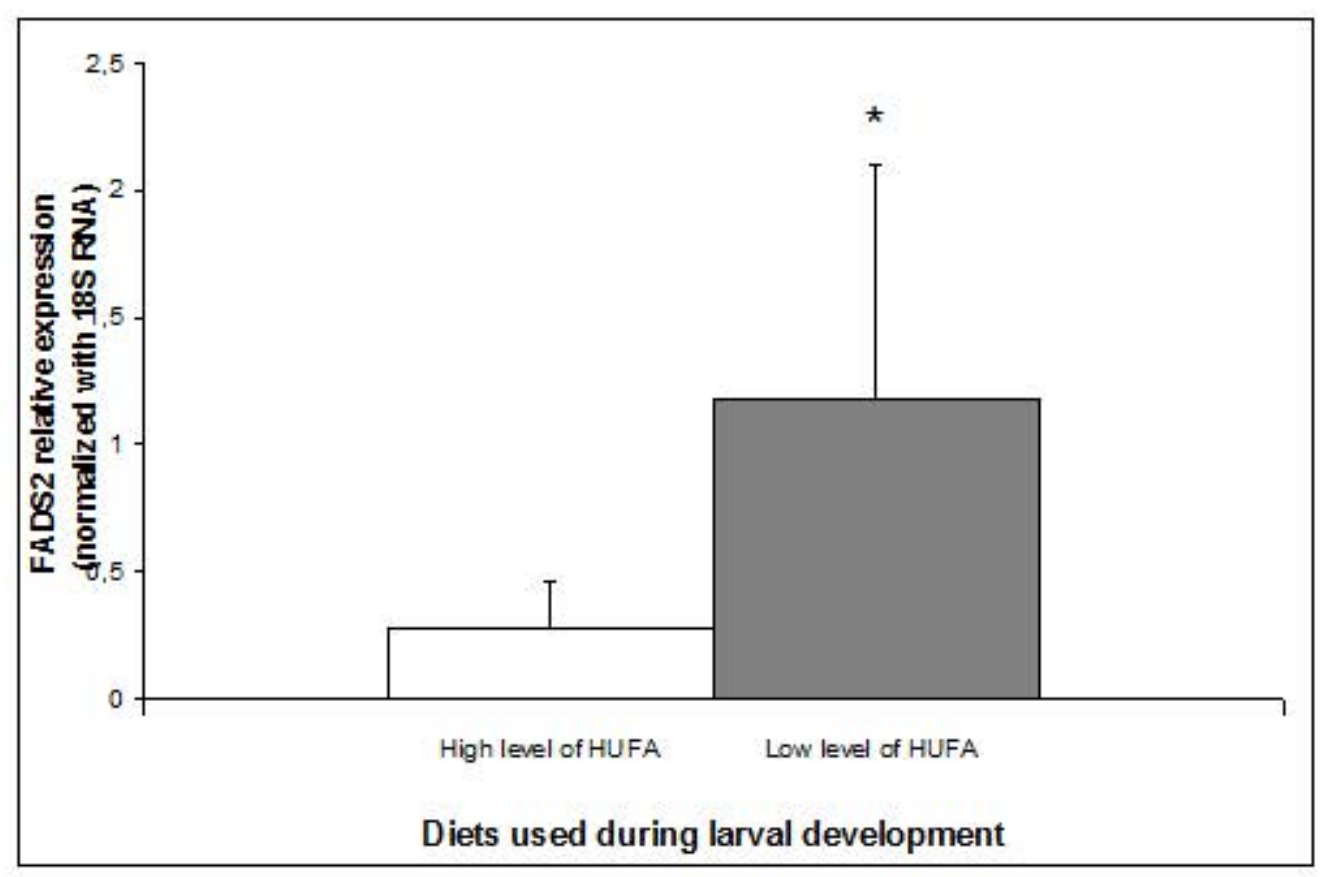


Table 1: Ingredients (\% Dry Matter) and fatty acids composition (\% sum of fatty acids) of the diets containing high (H) and low (L) HUFA levels.

Diets

H

$\mathbf{L}$

Ingredients (\% DM)

Fish meal

Defatted fish meal

$54,0 \quad 16,5$

CPSP 90

0

36

Soybean oil

10,0

10,0

Lecithin blend (soybean+rapeseed)

$0,0 \quad 3,5$

Marin phospholipids

$21,0 \quad 23,0$

Vitamins premix

$2,0 \quad 0,0$

Minerals premix

$1,0 \quad 1,0$

Cellulose

1,0

1,0

Liant

2,0

0,0

1,0

1,0

Fatty acids composition (\% sum of fatty acids)

\begin{tabular}{lcc}
\hline$\sum$ saturates & 4,3 & 3,2 \\
\hline$\sum$ monoenes & 5,2 & 5,0 \\
\hline $18: 2 \mathrm{n}-6$ & 4,1 & 5,5 \\
\hline $20: 2 \mathrm{n}-6$ & 0,0 & 0,0 \\
\hline $18: 3 \mathrm{n}-6$ & 0,0 & 0,0 \\
\hline $20: 4 \mathrm{n}-6$ & 0,1 & 0,0 \\
\hline$\sum \mathrm{n}-6$ PUFA & 4,2 & 5,5 \\
\hline $18: 3 \mathrm{n}-3$ & 0,6 & 0,8 \\
\hline $18: 4 \mathrm{n}-3$ & 0,2 & 0,0 \\
\hline $20: 3 \mathrm{n}-3$ & 0,0 & 0,0 \\
\hline $20: 4 \mathrm{n}-3$ & 0,1 & 0,0 \\
\hline $20: 5 n-3$ & 0,5 & 0,1 \\
\hline $22: 5 \mathrm{n}-3$ & 0,1 & 0,0 \\
\hline $22: 6 \mathrm{n}-3$ & 0,7 & 0,2 \\
\hline$\sum \mathrm{n}-3$ PUFA & 2,2 & 1,1 \\
\hline EPA+DHA & 1,2 & 0,3 \\
\hline total lipid & 15,9 & 14,8 \\
\hline
\end{tabular}


Table 2: Primers used for real time PCR analysis.

\begin{tabular}{|c|c|c|c|c|c|}
\hline Genes & Primers & Species & $\begin{array}{l}\text { Amplicon } \\
\text { sizes }\end{array}$ & Efficiency & Sequences (5’- 3’) \\
\hline \multirow{4}{*}{ Fads2 } & FADS2-1 forward & Rainbow trout \& E. sea bass & \multirow{2}{*}{ 96bp } & \multirow{2}{*}{$99.5 \%$} & GCTGGAGARGATGCCACGGA \\
\hline & FADS2-1 reverse & Rainbow trout \& E. sea bass & & & TGCCAGCTCTCCAATCAGCA \\
\hline & FADS2-2 forward & European sea bass & \multirow{2}{*}{ 202bp } & \multirow{2}{*}{$99.8 \%$} & ССТTСАСТGСТСТТСАТСССАА \\
\hline & FADS2-2 reverse & European sea bass & & & CCCAGGTGGAGGCAGAAGAA \\
\hline \multirow{2}{*}{$18 S$} & 18S forward & European sea bass & \multirow{2}{*}{ 76bp } & \multirow{2}{*}{$99.2 \%$} & TGGTTCCTTTGATCGCTCTT \\
\hline & 18S reverse & European sea bass & & & AGCAGCTCGTTGGCATGTAT \\
\hline \multirow{2}{*}{$E f 1 \alpha$} & EF1 forward & Rainbow trout \& E. sea bass & \multirow{2}{*}{ 155bp } & \multirow{2}{*}{$98.5 \%$} & ACAAGCCCCTYCGTCTGCC \\
\hline & EF1 reverse & Rainbow trout \& E. sea bass & & & GCATCTCCACAGACTTSACCTC \\
\hline
\end{tabular}

